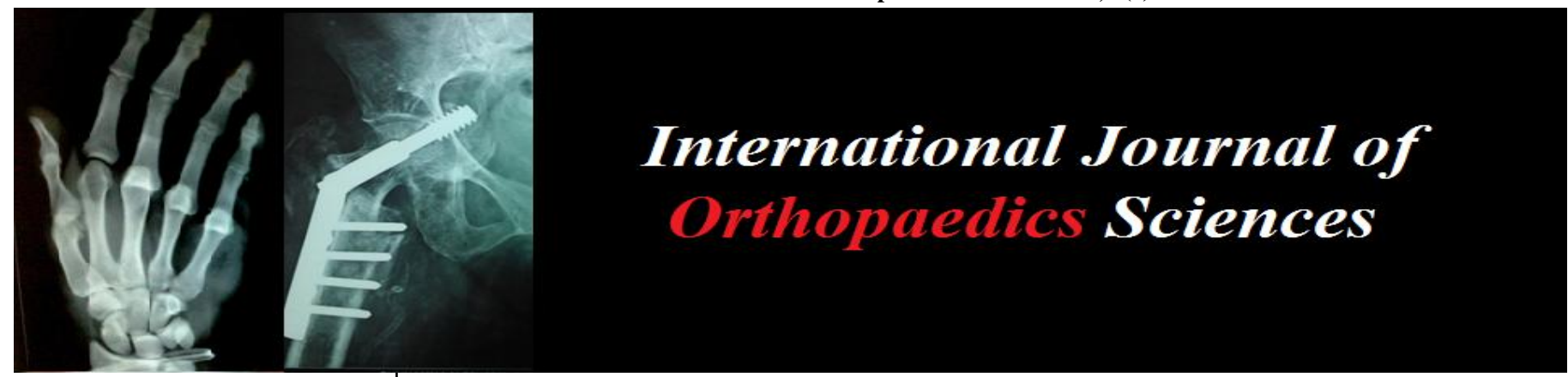

ISSN: 2395-1958

IJOS 2019; 5(2): 74-76

(C) 2019 IJOS

www.orthopaper.com

Received: 26-02-2019

Accepted: 27-03-2019

Avtar Singh Balawat

Assistant Professor, Dept of

Orthopedics, SMS Medical

College, Jaipur, Rajasthan, India

Navin Kumar Singh

Associate Consultant, Dept of Orthopedics, Churu

Multispeciality Hospital and

Research Centre, Churu,

Rajasthan, India

Amit Roy

Associate Consultant, Dept of

Orthopedics, Medica

Superspeciality Hospital

Kolkata, West Bangal, India

Bhavuk Garg

Associate Professor, Dept of Orthopedics, All India Institute of Medical Sciences (AIIMS),

New Delhi, India
Correspondence

Navin Kumar Singh

Associate Consultant, Dept of

Orthopedics, Churu

Multispeciality Hospital and

Research Centre, Churu,

Rajasthan, India

\section{Patient specific custom made distal ulnar prosthesis for giant cell tumour distal ulna: A case report}

\author{
Avtar Singh Balawat, Navin Kumar Singh, Amit Roy and Bhavuk Garg
}

DOI: https://doi.org/10.22271/ortho.2019.v5.i2b.17

\begin{abstract}
Giant cell tumour of the distal ulna is considered more aggressive resulting in to inferior oncological and functional outcome after conventional treatment methods. We are reporting a case of giant cell tumour of campanacci stage 3 ocurring at distal end of ulna of dominant extremity in a 40 -years-old female. She was treated with enblock resection of distal ulna with patient specific custom made distal ulnar prosthesis with reconstruction of distal radio ulnar joint using extensor carpi ulnaris tendon. After 24 months of followup there is no local or distant recurrence. Functionally paitent is having $90^{\circ}$ supination, $80^{\circ}$ pronation, $80^{\circ}$ extension and $70^{\circ}$ flexion of right wrist. To validate our study there has to be large series involving significant number of patients.
\end{abstract}

Keywords: Giant cell tumour, ulna, enblock resection, Camapanacci

\section{Introduction}

Giant cell tumor (GCT) of the distal ulna is quite rare. It constitutes $0.45 \%$ to $3.2 \%$ of total giant cell tumors occurring in human body ${ }^{[1]}$. Giant cell tumour of bone is locally aggressive benign lesion but lesions of distal forearm are considered more aggressive resulting in to higher recurrence rate after conventional treatment methods ${ }^{[2,7]}$. Enblock resection of distal ulna provides excellent oncological results but compromises function ${ }^{[3,4]}$ Recently there has been increased enthusiasm for reconstruction of distal ulnar segment with distal ulnar prosthesis along with distal radio ulnar joint (DRUJ) reconstruction leading to excellent functional outcomes ${ }^{[5,6]}$ The availability of these implants and cost are significant prohibitory factors especially in India.

We wish to present preoperative planning, medico-legal issues faced, innovative solution and successful outcome of a Campanacci stage three GCT of distal end ulna of right-sided dominant extremity in a 40-years-old female patient.

Case History A 40-years-old female patient presented to us with 11 months history of pain and swelling on the ulnar aspect of distal forearm in her dominant right upper extremity. It was insidious in onset, gradually progressive without any history of trauma, fever, weight loss, or any other swelling in the body. On clinical examination swelling was of five $\mathrm{x}$ five $\mathrm{x}$ five $\mathrm{cm}$ size, globular in shape, present at the ulnar aspect of the distal forearm proximal to wrist joint, firm to hard in consistency, fixed to underlying bone with diffuse tenderness. The overlying skin was freely moveable without any sinus, discharge or scar mark. Radiographs of the distal forearm [Fig 1] showed juxta articular expansile lytic lesion involving epiphysio-metaphyseal region of distal ulna with cortical breach and soft tissue extension. As per Campanacci ${ }^{[7,8]}$ classification it was staged three. MRI of the forearm revealed hypointense lesion in T1 and hyperintense lesion in T2 sequences involving distal ulna with soft tissue component. Adjacent neurovascular bundles were free. CT chest showed no metastasis. Core needle biopsy from the lesion was consistent with diagnosis of GCT showing mononuclear tumour cells and osteoclastic multinuclear giant cells.

Pre op planning - Various treatment options were discussed with the patient and with consent, patient was planned for customized distal ulnar prosthesis. For which CT scan of left forearm was done and based on the CT measurements of normal distal ulna, distal ulnar prosthesis was customized. Prosthesis was made up of titanium and had two main parts: ulnar head and long stem [Fig 2]. 
Operative procedure- After giving combined general and regional anaesthesia and tourniquet inflation, incision was given over the ulnar aspect of the distal forearm centering over the tumor including biopsy mark. With careful dissection tumor was dissected from surrounding soft tissue leaving one $\mathrm{cm}$ cuff of normal tissue around the tumour. Ulna was proximally cut eight $\mathrm{cm}$ from the distal articular margin as predetermined by MRI. We preserved the TFCC (triangular fibro cartilage complex) and tumor was resected enblock. Frozen section was sent and found free of tumor tissue. Reaming of the ulnar stump was done and customized ulnar prosthesis was inserted. DRUJ reconstruction was done using lateral half of the extensor carpi ulnaris (ECU) and passing it in figure of eight fashion through the drill hole made in the ulnar aspect of the distal radius. Stability of the DRUJ and implantation was checked along with range of movement (ROM) of wrist.

Post op rehabilitation- Post operative radiographs of right wrist with forearm obtained (Figure 3). Patient was kept in above elbow slab for two weeks. Range of movement exercises were started thereafter. Patient was evaluated at one month, three months, six months, one year and recently after 24 months post operatively.

Outcome-There were no immediate postoperative complications. At the end of the 24 months, there was no local or distal recurrence. Patient is having $90^{\circ}$ supination, $80^{\circ}$ pronation, $80^{\circ}$ extension and $70^{\circ}$ flexion [Fig $4 \mathrm{a}-4 \mathrm{~d}$ ]. There is no sensory or motor deficit. Patient is pain free and grip strength is well maintained.

Patient Declaration Statement We certify that we have obtained all appropriate patient consent forms. In the form the patient has given her consent for her images and other clinical information to be reported in the journal. The patient understands that her name and initial will not be published and due efforts will be made to conceal her identity, but anonymity cannot be guaranteed."

Discussion: GCT of the distal ulna is known for its aggressiveness ${ }^{[2]}$. The conventional methods of treatment include curettage and filling the cavity with autograft or allograft or bone substitutes including poly methyl metha acrylate (PMMA) bone cement ${ }^{[8,9]}$ But these procedures are associated with high rate of recurrence along with morbidity associated with allografts and autografts ${ }^{[5]}$. To decrease the rate of recurrence, complete excision of the tumor is necessary. Darrach procedure, which was modified later by Dingman, has the advantage of complete excision of the tumour. But it does have complications like instability of the ulnar stump leading to radio ulnar convergence, ulnar carpal instability and resultant pain, weakness and decrease in grip strength, limited ROM, rupture of digital extensor tendons ${ }^{[10,}$ 12-17]. To overcome these complications procedures are described to stabilize ulnar stump but they do not restore functions optimally. Excision of distal ulna with distal ulnar prosthetic replacement is becoming most viable option now a days because it not only facilitate complete excision of the tumour but also preserves the function of wrist including grip strength $[14,16]$. However the currently available implants do not have sufficient sizes and lengths to fulfill the variable requirement in tumor cases. Moreover, distal ulnar prosthesis is not available in India. Thus we customized distal ulnar prosthesis for this 40-year-old female patient with GCT distal ulna. We stabilized DRUJ by making a sling of radial half of the ECU and passing it through drill hole in distal radius. After 24 months of follow-up patient is having near normal ROM, adequate grip strength without any local or distal recurrence.

We conclude that enblock resection with distal ulnar prosthesis is becoming gold standard for the treatment of GCT distal ulna. The cost and availability of the implants are hindrance for adopting this standard method of treatment. Indigenous customized implants can also result in excellent functional and oncological outcome in lieu of non-availability and cost of imported implants. Although to validate our outcome, we need statistically larger case series involving significant number of patients.

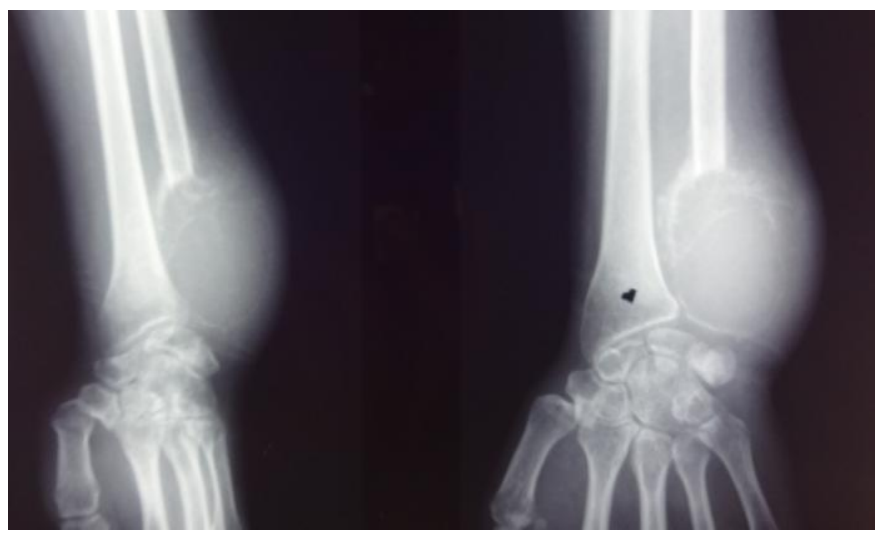

Fig 1: Preoperative radiograph of distal forearm anteroposterior and lateral view showing expansile lytic lesion of distal ulna.

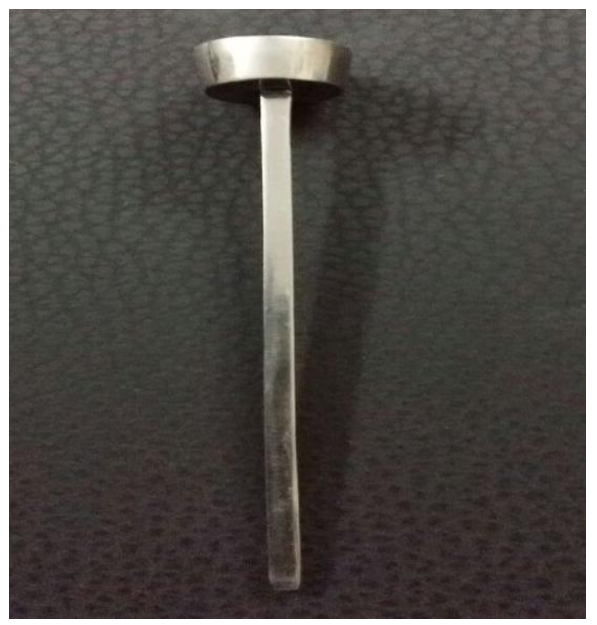

Fig 2: Custom made distal ulnar prosthesis with two parts: ulnar head and long stem.

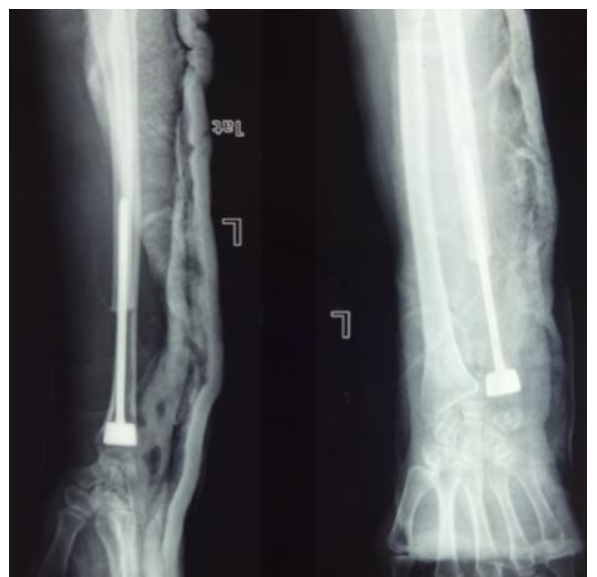

Fig 3: Post-operative radiograph of left forearm with custom made distal ulnar prosthesis in situ 

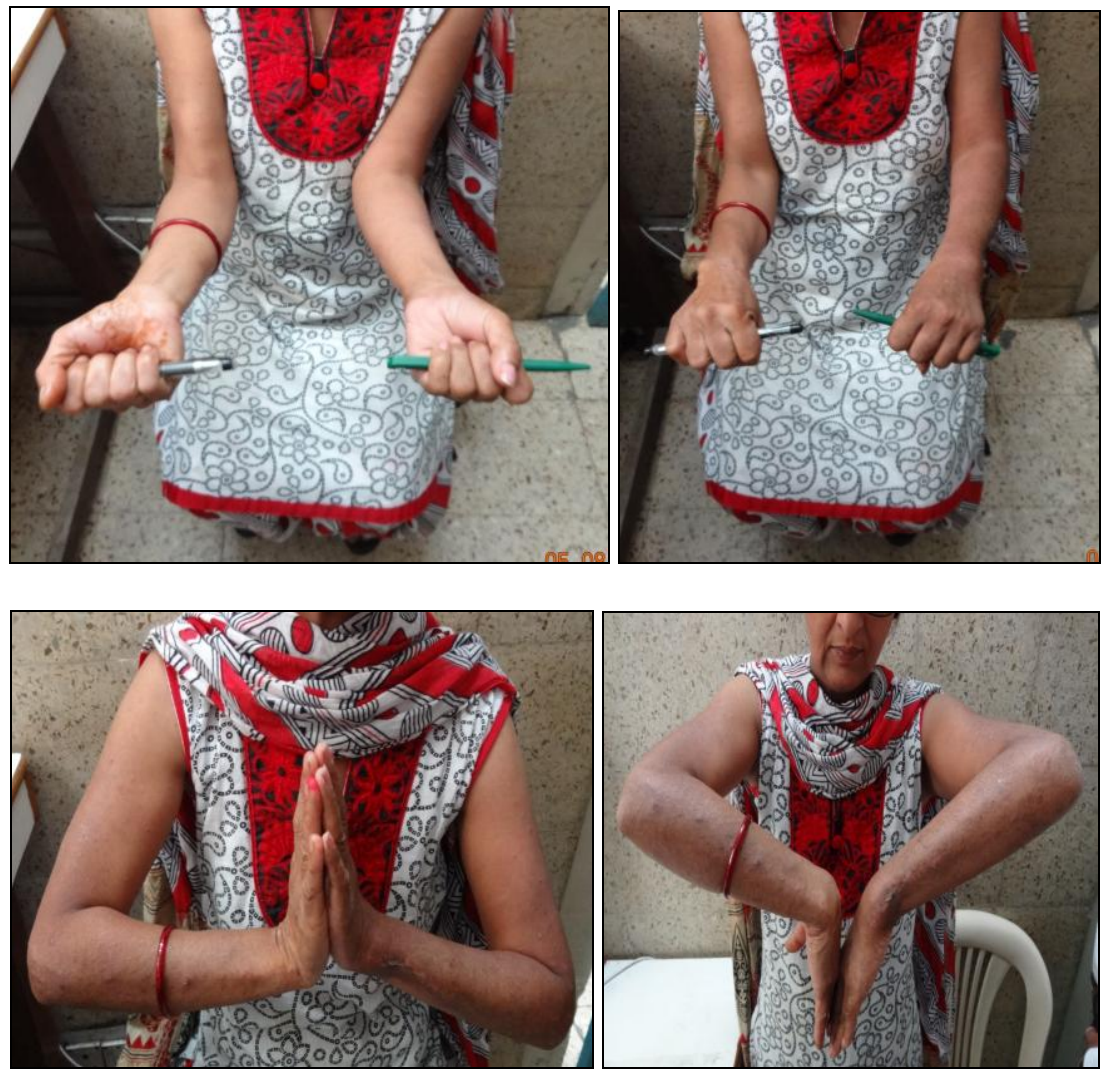

Fig 4a, 4b, 4c, 4d: Post-operative functional outcome after excision of distal ulna and replacement with distal ulnar prosthesis

\section{References}

1. Goldenberg RR, Campbell CJ, Bonfiglio M. Giant cell tumor of bone. An analysis of two hundred and eighteen cases. J Bone Joint Surg. 1970; 52A:619-664.

2. Harness NG, Mankin HJ. Giant cell tumor of the distal forearm. J Hand Surg. 2004; 29A:188-93.

3. Gordon KE, Dunning CE, Johnson JA, King GJW. Kinematics of ulnar head arthroplasty. J Hand Surg. 2003; 28B:551-8.

4. Sauerbier M, Hahn ME, Fujita M, Neale PG, Berglund LJ, Berger RA. Analysis of dynamic distal radioulnar convergence after ulnar head resection and endoprosthesis implantation. J Hand Surg 2002; 27A:425-434.

5. Scheker LR, Babb BA, Killion PE. Distal ulnar prosthetic replacement. Orthop Clin North Am 2001; 32:365-376.

6. Berger RA, Cooney WP. Use of an ulnar head endoprosthesis for treatment of an unstable distal ulnar resection: review of mechanics, indications, and surgical technique. Hand Clin 2005; 21:603-620

7. Campanacci M. Giant cell tumor. In: Campanacci M, editors. Bone and soft tissue tumors. 2nd ed. New York: Springer Verlag; 1999, 99-132.

8. Campanacci M, Baldini N, Boriani S, Sudanese A. Giantcell tumor of bone. J Bone Joint Surg 1987; 69A:106-114.

9. Rock M. Curettage of giant cell tumor of bone: factors influencing local recurrences and metastasis. Chir Organi Mov. 1990; 75(Suppl1):204-5.

10. Ferracini R, Masterson EL, Bell RS, Wunder JS. Distal ulnar tumors. Results of management by en bloc resection in nine patients and review of the literature. $\mathbf{J}$ Hand Surg. 1998; 23B:517-21.

11. Wurapa RK, Whipple R. Distal radioulnar allograft reconstruction after giant cell tumor resection. Am J Orthop. 2003; 32:397-400.
12. Newmeyer WL, Green DP. Rupture of digital extensor tendons following distal ulnar resection. J Bone Joint Surg. 1982; 64A:178-82.

13. Noble J, Arafa M. Stabilization of distal ulna after excessive Darrach's procedures. Hand 1983; 15:70-2

14. Roidis NT, Gorgoulias NE, Paraskevi LD, Konstantinos MN. Distal ulnar implant arthroplasty as a definitive treatment of arecurrent giant-cell tumor. J Hand Surg. 2007; 32A:1262-6.

15. Bieber EJ, Linschied RL, Dobyns JH, Beckenbaugh RD. Failed distal ulna resections. J Hand Surg [Am]. 1988; 13A:193-200.

16. Van Schoonhoven J, Fernandez DL, Bowers WH, Herbert TJ. Salvage of failed resection arthroplasties of the distal radioulnar joint using new ulnar head prosthesis. J Hand Surg. 2000; 25A:438-46.

17. Dingman PV: Resection of the distal end of the ulna (Darrachoperation); an end result study of twenty four cases. J Bone Joint Surg Am. 1952; 34A:893-900. 